\title{
A DITADURA DE 1964-1985 NA INICIAÇÃO À DOCÊNCIA: O ENSINO ENTRE O DEVER DE MEMÓRIA E AS DISPUTAS MIDIÁTICAS ${ }^{1}$
}

\author{
THE DICTATORSHIP OF 1964-1985 IN THE TEACHING INITIATION: THE \\ TEACHING BETWEEN THE MEMORY DUTY AND THE MEDIA STRUGGLES
}

\author{
Walter Francisco Figueiredo Lowande ${ }^{2}$ \\ Vinícius Pedro Fonseca ${ }^{3}$ \\ Pedro Otávio Carvalho Fernandes ${ }^{4}$
}

\begin{abstract}
RESUMO: Propomos algumas reflexões teóricas sobre os desafios de se ensinar a História da Ditadura de 1964-1985 em meio às guerras de memória sobre o período que se processam nas mídias eletrônicas. Esse debate relaciona-se, de maneira relevante, com as discussões a respeito dos problemas envoltos no tema da História Pública e da Mídia-Educação. Em seguida, apresentamos algumas das experiências e conclusões que desenvolvemos a este respeito a partir de ações desenvolvidas no Programa Institucional de Bolsas de Iniciação à Docência em 2017.
\end{abstract}

Palavras-chave: Ditadura de 1964-1985. Guerras de Memória. Mídia-Educação.

\begin{abstract}
We propose some theoretical reflections about the challenges related to the teaching of the history of 1964-1985's Brazilian dictatorship among the memory wars concerned to this period on the electronic media. This debate is relevantly linked to the discussions about the problems concerned to the theme of the public history. Therefore, we present some experiences and conclusions we have developed about this matter from actions that took place in the Institutional Scholarship Program of Teaching Initiation in 2017.
\end{abstract}

Keywords: Dictatorship of 1964-1985. Memory Wars. Media-Education.

\footnotetext{
${ }^{1}$ Este trabalho foi desenvolvido a partir das atividades de formação de professores possibilitada pelo PIBID/CAPES, no ano de 2017, antes, portanto, das reformulações pelas quais o programa passou recentemente. Agradecemos ao Prof. Dr. Luiz Sabeh e aos(às) estudantes e professoras do Ensino Básico que atuaram conosco no PIBID/UNIFAL-MG pela parceria e pela contribuição para a formulação das ideias aqui desenvolvidas por meio das diversas discussões que tivemos oportunidade de realizar ao longo de nossa atuação neste programa.

${ }^{2}$ Professor do curso de História, Licenciatura, da Universidade Federal de Alfenas-MG (UNIFAL-MG). Doutor em História pela UNICAMP.

${ }^{3}$ Graduando em História pela UNIFAL-MG. Bolsista do PIBID-História da UNIFAL-MG.

${ }^{4}$ Graduando em História pela UNIFAL-MG. Bolsista do PIBID-História da UNIFAL-MG.
} 


\section{Entre o dever de memória e as disputas midiáticas}

O ensino de conteúdos históricos relacionados ao período em que o país esteve sob a ditadura de 1964-1985 arremessa os(as) professores(as) do Ensino Básico numa verdadeira "guerra de memórias" (PEREIRA, 2015). Ao abordar o tema, eles(as) se deparam com o delicado campo da "História do Tempo Presente", que lida, nesse caso, com narrativas relacionadas a um tema "traumático e recente" (ROCHA, 2015). Trata-se de um "passadopresente", pois as pessoas que foram torturadas e que ainda estão vivas e os familiares daquelas que desapareceram ou foram assassinadas ainda clamam por justiça, ao passo que militares e civis envolvidos nesses crimes e suas respectivas corporações/instituições se esforçam em justificar ou negar os "excessos" da ditadura. Essa disputa provoca um combate entre narrativas em que o "poder de veto" dos fatos tem, muitas vezes, sucumbido ao apelo das "novas mídias".

As "revisões" e "negações" do período ditatorial têm ganhado cada vez mais força, a ponto de vários setores da população brasileira terem perdido o constrangimento de clamarem, publicamente, pelo "retorno da ditadura" ou por uma nova "intervenção militar". A própria impunidade, institucionalizada pela "Lei da Anistia" de 1979, pode ser considerada um fator responsável por uma "frágil inscrição" da memória do terrorismo de Estado em nosso país, o que tem alimentado diversos "revisionismos" e "negacionismos". Essas narrativas são articuladas por "redes de memória" (PEREIRA, 2015) que ganham força nas ferramentas virtuais de comunicação, a exemplo das redes sociais, sites de compartilhamento de vídeos e enciclopédias livres.

Diante disso, a historiografia teria o papel de "corrigir a memória e seus abusos" (PEREIRA; HERMETO, 2016). No entanto, o próprio campo historiográfico tem se dividido em função de posicionamentos políticos atrelados a distintas memórias da experiência ditatorial. Boa parte dos(as) historiadores(as) que se debruçam sobre o tema são também testemunhas dos eventos mais significativos do período, tendo alguns(mas) deles(as) 
participado ativamente de acontecimentos que hoje compõem de forma destacada as narrativas sobre o regime de exceção. ${ }^{5}$

Por outro lado, a memória política dos grupos de esquerda ou de direita tem provocado a produção de narrativas historiográficas que acabam deslizando para generalizações, ataques e contra-ataques em textos bastante acalorados. De um lado, historiadores(as) inspirados pelo materialismo dialético denunciam o revisionismo de autores(as) que culpabilizam a sociedade brasileira como um todo pelo golpe de 1964 - na polêmica que discute se é correto ou não chama-lo de "civil-militar" -; que substituem os determinismos econômicos e políticos pelos culturais; que desconsideram a luta de classes na análise do processo que conduziu ao golpe; e que minimizam o caráter repressor do regime militar propondo-lhe novas periodizações. ${ }^{6}$ Para além desses aspectos, de fato presentes entre autores(as) que ou romperam com a militância de esquerda (o caso de Daniel Aarão Reis Filho) ou assumem publicamente uma postura neo- (ou ultra-) liberal (o caso de Marco Antônio Villa), emergem de algumas obras

\footnotetext{
${ }^{5}$ Exemplo dos conflitos de interpretação historiográfica em função de memórias disputadas pode ser encontrado na polêmica travada em publicação organizada pelo historiador Daniel Aarão Reis Filho (REIS FILHO, 1997), em torno do livro O que é isso, companheiro? (1979), de autoria de Fernando Gabeira, a respeito do sequestro do embaixador estadunidense planejado por Franklin Martins e pelo próprio Reis Filho, que à época lideravam a Dissidência Comunista da Guanabara (FICO, 2017). O próprio Carlos Fico apelou recentemente para o recurso de autoridade baseado no pertencimento geracional, como reforço retórico para a desqualificação das críticas desferidas por autores(as) mais jovens: "O bom debate teórico e historiográfico depende da maturidade que advém de muitas leituras e do discernimento que nos permite identificar autores relevantes" (FICO, 2017, p. 6), ou "arvorar-se em especialista capaz de avaliar outrem soa presunçoso. Alego que tenho pesquisado os temas da ditadura militar, da historiografia brasileira e da teoria e metodologia da história nos últimos trinta anos" (FICO, 2017, p. 7).

${ }^{6}$ A respeito da polêmica em torno do termo "golpe civil-militar", Demian Bezerra de Melo se posiciona contra Daniel Aarão Reis, resgatando a tese de doutorado de René Dreyfuss, produzida no final da década de 1960, e mostrando que o uso do termo "civil-militar" generaliza a culpa do golpe para toda a sociedade brasileira, quando se tratou, na verdade, de um golpe do grande empresariado com participação da classe média, dos meios monopolistas de comunicação e da Igreja Católica sob a direção dos militares - de modo que uma nomenclatura mais correta seria "golpe empresarial-militar" (MELO, 2012). Carlos Fico questiona o embasamento teórico dos ataques marxistas ao "culturalismo", embora reconheça os problemas em torno de trabalhos que operam com a categoria "cultura política" e dos que defendem uma suposta contradição do processo de "modernização conservadora". No entanto, Fico também discorda da tese do consenso geral da "sociedade brasileira" com o golpe e das periodizações propostas por Reis Filho e Marco Antônio Villa para o regime militar, que o reduzem a uma institucionalização do regime de exceção restrita ao período que vai de 1968 a 1979 (FICO, 2017). Os argumentos de Fico sobre a categoria "cultura política" foram recentemente rebatidos ainda por Rodrigo Patto Sá Mota (MOTA, 2018).
} 
não-marxistas temas que são tabu no campo da memória da resistência ao golpe, como, por exemplo, a supervalorização do papel da resistência armada na luta contra os militares; os traumas causados pelo recrutamento de jovens estudantes numa disputa bélica desigual em relação ao terrorismo de Estado; um provável recrudescimento do regime de exceção em função das estratégias adotadas pelos movimentos de esquerda (FICO, 2017); e, nós acrescentaríamos, um comprometimento desses movimentos com as ideologias modernizadoras que mais os aproximam do que os afastam do papel autoritário cumprido pelo Estado brasileiro ao longo de sua trajetória. ${ }^{7}$

Desse modo, o(a) professor(a) que queira ou tenha condições de se amparar na produção historiográfica a respeito do período que vai de 1964 a 1985 (ou 1988) para orientar a preparação de suas aulas se embrenhará, também aí, numa complexa guerra de memórias. Não que uma versão única a respeito de um tema tão sensível fosse uma situação preferível, muito pelo contrário. No entanto, todos(as) nós que, de uma forma ou de outra, temos contato com o cotidiano da Educação escolar de nível Básico sabemos que um tal preparo para a elaboração de uma aula é, caso exista empiricamente, uma bela exceção. O livro didático, via de regra, continua sendo, portanto, uma ferramenta imprescindível para o trabalho pedagógico na Educação Básica. Em relação a isso, contudo, pesquisas recentes têm

\footnotetext{
${ }^{7}$ É óbvio que a já bastante farta historiografia a respeito deste regime ditatorial não se esgota nos temas elencados neste parágrafo. Dentre outros levantamentos historiográficos, sugerimos um interessante artigo escrito por Marcos Napolitano, que fala a partir da perspectiva da expectativa da aproximação da efeméride dos 50 anos do golpe (2014) e do início dos trabalhos da Comissão Nacional da Verdade (NAPOLITANO, 2011). Sobre a modernidade da esquerda marxista, a crítica materialista-dialética tem acusado de "pósmodernas" (MELO, 2012; MATTOS, 2008, apud FICO, 2017) qualquer tipo de desconfiança em relação à naturalização da ideologia segundo a qual a humanidade se tornará efetivamente livre a partir do momento em que dominar completamente a "natureza" comprometimento este exemplificado mais recentemente em Mészáros (2003). No entanto, desde o final da Segunda Guerra Mundial, trabalhos filosóficos, sociológicos e antropológicos têm chamado atenção para aquilo que hoje se constitui como uma crise mais abrangente do "Antropoceno", momento em que a ideia de domínio do sujeito do conhecimento moderno por sobre a natureza nos tem conduzido ao risco iminente do esgotamento dos recursos naturais indispensáveis à nossa vida no planeta. Sugerimos aqui apenas algumas obras, já clássicas, que apontam para o caráter historicamente construído desses processos de subjetivação e objetivação modernos e que também são naturalizados pelo paradigma marxista: Adorno e Horkheimer ([1947]), Latour (1994), Bauman (1998), Gumbrecht (1998), Deleuze e Guattari (2004) e Wagner (2010).
} 
demonstrado uma série de problemas preocupantes quanto se trata do material disponibilizado a respeito da ditadura de 1964-1985.

Helenice Rocha, por exemplo, constata, a partir da análise das 16 coleções escolhidas pelo Programa Nacional do Livro Didático (PNLD) de 2011, que essas narrativas não seriam compreendidas pelos leitores de forma adequada, haja vista que elas acabam reproduzindo as guerras de memórias historiográfica e midiáticas em forma de dicotomias simplificadas e, não raro, contraditórias. Um tal diagnóstico se prende ao fato, atestado por Rocha, de que essas coleções possuem lacunas e incongruências relativas aos mecanismos internos (incoerências e ausência de interligação entre os assuntos) e externos (impacto das confusões geradas pelas guerras de memória) ao texto, o que produz "um certo embaçamento nos potenciais de sentido dessas narrativas", afinal "os leitores poderão não entender bem nem a narrativa em sua dimensão factual nem sua proposta analítica, fragilizada em uma síntese histórica pouco clara" (ROCHA, 2015, p. 116).

Partindo da consideração da "dívida ética" dos "professoreshistoriadores-cidadãos" em relação ao que se passou, Mateus Pereira e Miriam Hermeto constatam que os livros didáticos têm, no entanto, cedido "à tentação da memória em detrimento da história" (PEREIRA e HERMETO, 2016, p. 11). Em seu levantamento constata-se, por exemplo, que o tema da "arte engajada" tem sido interpretado, nos livros didáticos, mais em função das memórias dos seus organizadores, impulsionados pelo dever de memória de "dar voz" aos que foram silenciados, do que das discussões propriamente historiográficas. ${ }^{8} \mathrm{O}$ risco de um dever de memória desvinculado de um trabalho de memória ${ }^{9}$ é a criação de heróis e vilões a partir de ações que não correspondem à realidade. Ao invés disso, seria preciso privilegiar a pesquisa histórica sistemática sobre o tempo presente como ponto de partida para a produção dos livros didáticos, pois ela "pode

\footnotetext{
${ }^{8}$ Neste caso, predominam as interpretações segundo as quais a arte engajada seria uma produção feita em relação à censura militar, e não como um tipo de ação ligado a um projeto de transformação social anterior. (PEREIRA; HERMETO, 2016, p. 2).

${ }^{9} \mathrm{O}$ trabalho de memória visaria corrigir os excessos do dever de memória, associando-se ao trabalho de crítica histórica, de esquecimento e de luto (PEREIRA; HERMETO, 2016, p. 1).
} 
levar a considerar não apenas resistência ou legitimação, mas a dinâmica dos jogos de aceitação, acomodação, resistência e dominação implicados na relação Estado/sociedade na Ditadura Militar" (PEREIRA; HERMETO, 2016, p. 11).

Além disso, os livros didáticos têm apresentado, em geral, uma ideia de inevitabilidade do golpe de 1964, graças a uma tradição interpretativa ainda amarrada às causalidades lineares. Segundo Mateus Pereira e Andreza Pereira, essa concepção precisaria ser urgentemente problematizada, pois

[...] é importante perceber que os livros didáticos não são uma mera transposição de um saber acadêmico para um saber escolar. As disciplinas escolares não são reflexo nem vulgarização dos saberes da pesquisa acadêmica. Ensinar, não é, portanto, simplificar e vulgarizar. Deveria ser, antes de tudo, fazer pensar, problematizar (PEREIRA; PEREIRA, 2011, p. 210).

Percebe-se, portanto, que as ideias de um tempo múltiplo ou multidirecionado, repleto de possibilidades não realizadas $e$ descontinuidades está ausente dos livros didáticos - ao menos das 60 obras analisadas por Pereira e Pereira.

Além dos problemas narrativos presentes nos livros didáticos, é preciso considerar a competição desigual que eles enfrentam em relação a outros tipos de mídia. Como nos lembra Jurandir Malerba, "editores, publicitários e homens de mídia em geral descobriram que o passado pode representar bons negócios" (MALERBA, 2014, p. 29). No Brasil, os(as) historiadores(as) enfrentaram com um certo atraso o campo da "História Pública", de modo que, aqui, "a perícia narrativa e as articulações mercadológicas parecem ser suficientes para garantir a qualquer leigo 0 domínio do ofício" (MALERBA, 2014, p. 31-32), o que acontece justamente num momento em que a demanda social pelo conhecimento histórico está "bombando". É interessante notar que os gestores da Educação no Brasil têm ido na contramão da explosão do número de revistas, sites, canais, jogos, filmes, novelas, séries e blogs históricos: por aqui a História tem sido, aos poucos, expurgada dos curricula, primeiro para ceder espaço às 
matemáticas e à língua portuguesa (MALERBA, 2014, p. 34), depois para atender às demandas do mercado na recente "reforma" do Ensino Médio.

Todavia, o problema não se restringe apenas à qualidade questionável dessa proliferação de produtos historiográficos para o consumo de massa, como atesta Malerba. Para além da má qualidade, o principal problema é a má fé, ao menos no que diz respeito aos conteúdos afeitos à ditadura de 1964-1985. É certo que com os relatórios da Comissão Nacional da Verdade, estaríamos de modo geral passando, de acordo com Mateus Pereira, de um "regime de não inscrição" para um regime de "inscrição frágil" da memória do terrorismo de Estado desse período. Todavia, essa passagem "sutil e etérea não tem necessariamente levado à transformação da 'memória dividida' em uma 'memória compartilhada" (PEREIRA, 2015, p. 865). No campo de guerra das novas mídias, é a "estrutura temporal da negação e, em alguma medida, do revisionismo" que tem levado a melhor. Essa perspectiva se assenta "numa concepção fatalista, determinista e homogênea do tempo histórico", que "tende a afirmar que o Golpe de 1964 só existiu porque não havia outra alternativa; ele foi inevitável. Se não fosse o Golpe, teria havido um golpe e uma ditadura comunista" (PEREIRA, 2015, p. 870).

É possível encontrar hoje na internet uma profusão de narrativas a serviço dessa "negação" da culpa dos envolvidos com a tortura e com os assassinatos nesse período ditatorial. Os "revisionistas", historiadores leigos ou profissionais, costumam "esmigalhar" um evento e produzir, a partir daí, uma nova interpretação de aspecto lógico e repleta de meias verdades dificilmente visíveis a um público sem uma formação historiográfica crítica suficiente. Trata-se, como descobre Pereira, de um trabalho sistemático, "fundado em uma retórica que idealiza, distorce, dissimula, justifica e milita por algum tipo de autoabsolvição", compondo um conjunto de novas "inscrições" realizadas por atores que fazem parte ou se identificam com uma complexa "comunidade de memória em rede" (PEREIRA, 2015, p. 880). 
A ampla repercussão e aceitação desse tipo de memória forjada se deve, portanto, a um trabalho sistemático que se configurou, recentemente, como reação a um governo de "esquerda" no poder desde 2003. É importante acrescentar que essas "redes de memória" estão articuladas transnacionalmente a poderosos grupos empresariais, como já deixou demonstrado artigo da historiadora Katia Baggio (BAGGIO, 2016). Com isso, temos uma "comunidade de memória" bastante fortalecida e que, além disso, é

[...] produto e produtora de uma visão da sociedade e da história brasileira que defende e reproduz a dimensão hierárquica, violenta e desigual da nossa história. A negação, em geral, pretende inibir alguma coisa [...]. No nosso caso, qualquer tipo de transformação da sociedade em dimensões mais justas e democráticas" (PEREIRA, 2015, p. 886).

Impede-se, assim, a construção de uma "justa memória", capaz de dar visibilidade aos crimes negados pelo conjunto de atores, agora um pouco melhor conhecidos, em função das apurações da Comissão Nacional da Verdade e de suas repercussões.

Por tudo isso, acreditamos que uma estratégia fundamental para o enfrentamento dessa guerra de memórias e para a reconstrução de uma "justa memória" do golpe passa pela "mídia-educação". (BÉVORT; BELLONI, 2009). As narrativas educativas das escolas básicas perdem cada vez mais a autoridade diante das plataformas digitais, que "subverteram as bases da produção e circulação das narrativas sobre o passado" (MALERBA, 2017, p. 142). A Educação Básica, no entanto, tem incorporado essas novas tecnologias, quando muito, a partir das velhas formas de construção e apresentação do conhecimento histórico. Isso significa que, enquanto o advento da internet, com sua linguagem hipertextual, representou um impacto incomensurável sobre a cultura histórica, a Educação escolar tem se mantido presa a práticas que remontam ao surgimento da disciplina histórica no século XIX. Isso tem sido aproveitado muito bem, como vimos, pelos aliciadores externos da negação e do revisionismo a respeito do golpe. 
Foram estes os desafios com os quais nos deparamos quando, nas atividades do Programa de Iniciação à Docência de nossa universidade, nos vimos diante do desafio de pensar em atividades para três turmas distintas que estavam trabalhando com os conteúdos afeitos ao golpe de 1964. Nas próximas seções, trataremos dos diagnósticos que realizamos, das estratégias que adotamos e das conclusões às quais chegamos ao longo deste último semestre, quando nos propusemos a encarar esses problemas.

\section{O encontro dos(as) docentes em formação com o ensino sobre a ditadura de 1964-85: diagnósticos e atividades}

O Programa Institucional de Bolsas de Iniciação à Docência (PIBID), Área de História, da nossa universidade desenvolve atividades junto às escolas estaduais de Ensino Básico da cidade desde 2011. A população estimada da cidade sul-mineira de Alfenas, na qual atuamos, era de 79707 habitantes em 2017, ${ }^{10}$ com 9560 matrículas no Ensino Fundamental, sendo 4569 delas nos anos finais, e 2935 matrículas no Ensino Médio no ano de 2016 (INEP, 2017). Este artigo apresenta a experiência que tivemos com, aproximadamente, 80 estudantes do 90 ano, num universo de 667 matrículas para esta fase do Ensino Fundamental na rede estadual da cidade e, aproximadamente, 80 estudantes da $3^{a}$ série do Ensino Médio, de um total de 571 matrículas para essa série no ensino público estadual desta cidade - uma amostragem aproximada, portanto, de respectivamente $12 \%$ e $14 \%$ do total de matrículas para os $90^{s}$ anos do Ensino Fundamental e $3^{\text {as }}$ séries do Ensino Médio estaduais da cidade. ${ }^{11}$

Pudemos contar, em 2017, com uma equipe composta da seguinte forma: dois coordenadores, que são professores do magistério superior responsáveis pela definição das estratégias comuns de ação e pela orientação dos projetos elaborados pelos(as) bolsistas; quatro supervisoras, que são professoras das turmas do Ensino Básico com as quais

\footnotetext{
${ }^{10}$ Disponível em: https://cidades.ibge.gov.br/brasil/mg/alfenas/panorama. Acesso em: 26 dez. 2017.

${ }^{11}$ Cálculos feitos com base nos dados apresentados em INEP (2017).
} 
desenvolvemos as atividades pedagógicas de iniciação à docência; e vinte e um bolsistas, que são licenciandos(as) em História e que desenvolvem as atividades diretamente nas escolas. Os(as) bolsistas compõem grupos de duas ou três pessoas a fim de que cada um deles trabalhe com uma turma específica, de acordo com a disponibilidade apresentada pelas supervisoras.

No segundo semestre de 2017 nós definimos, preliminarmente e em conjunto, que todos os grupos deveriam explorar as novas mídias como ferramenta educacional. Os conteúdos abordados obedeceram ao currículo e ao cronograma que estavam sendo trabalhados pelas supervisoras. Por isso, quatro dos nossos seis grupos se depararam com o desafio de preparar uma atividade pedagógica relacionada ao período ditatorial de 1964-1985, tendo em vista que esse foi o conteúdo trabalhado pelas duas turmas da $3^{a}$ série do Ensino Médio e pelas duas turmas do 90 ano do Ensino Fundamental com as quais estabelecemos essa parceria formativa. ${ }^{12}$

No primeiro contato dos(as) bolsistas com as turmas do Ensino Básico realizamos diagnósticos que nos ajudaram a conhecê-las um pouco melhor antes de propormos nossas atividades. Esses diagnósticos consistiram, nesse nosso caso, em conversas estabelecidas entre os(as) bolsistas e os estudantes do Ensino Básico a fim de conhecermos três aspectos que se relacionam com as discussões indicadas no início deste artigo: 1) se os(as) estudantes se interessavam ou não por conteúdos chamados "históricos", e, em caso positivo, o que caracterizaria esse interesse; 2) quais informações/interpretações eles(as) possuíam/construíram a respeito da ditadura de 1964-1985; 3) qual seria a fonte dessas informações/interpretações.

A respeito do primeiro aspecto, ou seja, sobre o interesse pelos conteúdos relacionados ao Ensino de História, obtivemos respostas positivas. Os motivos apontados foram a simpatia para com os métodos adotados por uma professora em específico e a percepção de que o conhecimento histórico pode ser uma ferramenta útil para a compreensão

\footnotetext{
12 Os relatos que seguem baseiam-se nas reuniões coletivas que realizamos mensalmente ao longo deste segundo semestre de 2017, ao lado dos relatórios de diagnóstico e de atividades produzidas pelos(as) bolsistas e arquivados no nosso "Sistema de Cadastro de Projetos do PIBID".
} 
do presente. É possível que este interesse também esteja relacionado, como mostramos anteriormente, ao significativo espaço que o passado tem encontrado atualmente nas mídias comerciais. No entanto, isso não significa, necessariamente, apreço pelos conteúdos históricos escolares: em um dos grupos, por exemplo, um dos estudantes nos disse que gostava de estudar História até certo ponto, sobretudo quando o tema estava relacionado ao período militar. De acordo com ele, aquilo que se conta sobre a ditadura está carregado de tendências ideológicas de esquerda, e seus pais e avós disseram a ele que o período compreendido entre 1964-85 foi o melhor momento do país. Para ele, tratava-se de um "regime" iniciado por uma "revolução", e não de uma "ditadura" iniciada por um "golpe".

Sobre as informações/interpretações a respeito da ditadura de 1964/85 encontramos respostas variadas. Em geral os(as) estudantes da $3^{a}$ série do Ensino Médio demonstravam alguma familiaridade com o assunto. Alguns(mas) estudantes externaram a interpretação segundo a qual não teria havido propriamente uma ditadura entre 1964 e 1985, mas um "regime militar" que se impôs contra uma onda comunista que se articulava para tomar o Brasil. Outros(as) apresentaram uma imagem de uma ordem social positiva, de uma realidade permeada por maior segurança urbana e corrupção inexistente, seja na esfera pública ou na iniciativa privada. Nos casos em que os(as) bolsistas optaram pela abordagem de brainstorm, com a indicação das principais noções surgidas em meio à discussão na lousa como forma de composição de um quadro geral da diversidade de percepções, a participação dos(as) estudantes do Ensino Básico tendeu a ser mais acalorada, ancorando os temas do passado ditatorial às disputas políticas presentes, a exemplo de uma possível disputa presidencial entre Lula e Bolsonaro em 2018, algo que nos pareceu bastante significativo. No caso em que a estratégia foi solicitar que os(as) estudantes do 90 ano indicassem numa folha de papel o que eles(as) sabiam sobre o período ditatorial de 1964-85, eles(as) demonstraram, no entanto, um grande desconhecimento a respeito do próprio conceito de "ditadura", apresentando dificuldades em relacionar a experiência política do nosso 
passado recente a um quadro ditatorial, ou mesmo a entender o que poderia ou não caracterizar o conceito de ditadura. Isso foi algo que nos chamou a atenção tanto para as diferenças formativas existentes entre o último ano do Ensino Fundamental e a última série do Ensino Médio, por um lado, quanto para um possível silenciamento em relação ao tema, justo em instituições escolares que foram fundadas no período ditatorial.

Com relação às fontes de informação/interpretação sobre o período, os(as) estudantes indicaram os canais do YouTube, algumas canções e os relatos dos mais velhos. ${ }^{13}$ As atrocidades do regime são caracterizadas então, a partir dessas fontes, como um "mal necessário" ou uma "exceção" diante da defesa contra o espectro do comunismo ou da necessidade do desenvolvimento econômico e de uma política de segurança nacional. Essas versões, além de relativamente sedimentadas na memória das gerações que viveram o período, também têm sido reforçadas e reconstruídas, portanto, por meio dos espaços ocupados na internet pelos que se posicionam pela negação/revisão das interpretações de esquerda a respeito daquele processo.

Esses diagnósticos nos levaram a perceber, portanto, que os(as) estudantes do Ensino Básico têm tido, de modo geral, contato com diversas interpretações a respeito da ditadura de 1964-85. Essas interpretações lhes são apresentadas em diferentes linguagens e formas narrativas, de modo que esses(as) jovens em idade escolar estão posicionados em meio a um verdadeiro fogo cruzado nos diversos campos de batalha dessa "guerra de memórias". Em geral eles(as) opinam a respeito do assunto não com base nos saberes escolares, mas a partir das informações/interpretações obtidas das mídias eletrônicas e de vozes que Ihes soam mais confiáveis que as dos professores, como as dos próprios pais e avós que testemunharam o período.

De modo geral, duas preocupações centrais emergiram dessas primeiras impressões. A primeira delas foi dar a conhecer aos(às) estudantes do Ensino Básico noções elementares a respeito do tema dos

\footnotetext{
${ }^{13}$ Foram mencionados o canal "Nostalgia", de Felipe Castanhari, alguns vídeos de Olavo de Carvalho e algumas canções do período, a exemplo de "Alegria, alegria", de Caetano Veloso, e "Para não dizer que não falei das flores", de Geraldo Vandré.
} 
direitos humanos, algo que se percebeu ausente das opiniões expressas nas atividades de diagnóstico. A segunda foi instrumentalizar esses(as) estudantes para uma utilização crítica das mídias impressas e eletrônicas, levando-os(as) a perceber que essas ferramentas de comunicação não são neutras e podem ser utilizadas para diferentes finalidades de memorização e esquecimento. Um dos grupos procurou tratar do tema a partir da questão mais específica da violação dos direitos das populações indígenas no Brasil. Todos os grupos também planejaram estratégias de historicização de conceitos como os de "golpe", "ditadura" e "revolução", uma vez que eles continuam expressando, como pôde ser notado nos diagnósticos, batalhas semânticas diretamente atreladas às "guerras de memória" das quais estamos tratando neste artigo. Para o caso daquelas turmas que ainda não haviam alcançado uma compreensão mínima a respeito do conceito de ditadura, optou-se por comparar a ditadura de 1964-1985 com outros contextos ditatoriais, como, por exemplo, o Estado Novo e o nazismo alemão, que já eram um pouco melhor conhecidos pelos(as) estudantes do 90 ano. $^{14}$

Os grupos que insistiram em uma estratégia expositiva para o tratamento dos problemas elencados acima ficaram menos satisfeitos com os resultados das atividades que propuseram. Uma das frustrações apresentadas pelos grupos que empregaram esse método foi a baixa participação dos(as) estudantes nos momentos abertos para o debate. Um outro caso é bastante interessante: quando um dos grupos propôs que os(as) estudantes se posicionassem a respeito de duas narrativas jornalísticas que apresentavam interpretações contrárias a respeito das relações entre Estado e populações indígenas no Brasil durante a ditadura, boa parte deles(as) simplesmente copiou trechos das próprias fontes impressas para apresentar como suas "respostas", reproduzindo, deste modo, um tipo de prática avaliativa mecanizada e que pouco contribui para uma atitude crítica diante das diversas fontes de informação/interpretação existentes.

${ }^{14}$ É necessário, no entanto, tomar cuidado com as comparações em História. A este respeito, cf. Werner e Zimmermann (2003), Seigel (2005) e Weinstein (2013). 
Outra estratégia adotada foi privilegiar a atividade de pesquisa desenvolvida pelos(as) próprios(as) estudantes do Ensino Básico. Neste caso, a ideia era problematizar o confronto entre informações, interpretações e memórias a partir das narrativas encontradas por eles(as) mesmos(as) nas mídias digitais e nos relatos fornecidos por seus familiares que vivenciaram diretamente o período ditatorial. Essa abordagem também suscitou, no entanto, uma série de problemas no que diz respeito ao uso das ferramentas digitais.

Em primeiro lugar, foi importante considerarmos que os mecanismos de busca disponíveis na internet também não são neutros. É sabido que os principais sites de busca e redes sociais realizam seus procedimentos de ordenação das informações apresentadas aos seus usuários com base em algoritmos, que operam tanto a partir do histórico individual de navegação quanto de interesses de mercado. Isso significa que esses produtos cibernéticos criam "bolhas ideológicas", isto é, a ilusão de que as informações disponíveis confirmam a visão de mundo do usuário a fim de conquistar a sua simpatia, ao mesmo tempo em que conectam esses anseios individuais aos produtos de seus investidores. Foi justamente essa estratégia que possibilitou o processo de oligopolização do mercado de dados nas mãos de gigantescas data brokers como o Facebook, o Google, o Twitter, o Amazon etc. (PINTO; MÓDOLO, 2017).

Faz-se necessária, portanto, a intermediação do(a) educador(a) nesse processo de ensino/aprendizagem que também é mídia-educativo. Os(as) estudantes têm 0 direito de saber que os mecanismos de visibilidade/invisibilidade ou lembrança/esquecimento não são meramente técnicos ou neutros, mas obedecem a direcionamentos políticos num campo de disputas assimétrico. Por causa disso consideramos ter sido acertada a opção por equilibrar os relatos que na internet estão visíveis com pesos totalmente diferentes. Para isso foi apresentado aos(às) estudantes os 
depoimentos de ambas as partes, torturados(as) e torturadores, apresentados à Comissão Nacional da Verdade e disponíveis no YouTube. ${ }^{15}$

Em segundo lugar, verificamos algumas barreiras no que diz respeito ao uso dos meios digitais nas escolas de Ensino Básico no estado de Minas Gerais. A Lei Estadual no 14.486 de 2002, proíbe o uso de telefones celulares em sala de aula, dificultando, assim, o direcionamento dessas ferramentas para um trabalho de Mídia-Educação. Além disso, as salas de informática ainda são restritas a um suposto "uso correto" que, em essência, se caracteriza pela transposição da cultura escolar do século XIX para as mídias eletrônicas do século XXI. Em outras palavras, isso significa que a linguagem hipertextual da internet - ou seja, a possibilidade de enriquecimento da leitura por meio do estabelecimento de links com outros textos - é reprimida por uma vigilância que cobra uma postura "monotextual", ou melhor, por um disciplinamento que tolhe a criatividade dos(as) estudantes cobrando-Ihes um percurso cognitivo prévio e objetivamente prescrito.

O que foi dito acima pôde ser notado no comportamento furtivo dos(as) estudantes na sala de informática. O que eles(as) desejavam na verdade era cuidar de suas timelines no Facebook, de seus perfis no Instagram e em plataformas de jogos online, viralizar suas hashtags, enfim, cultivar os seus múltiplos avatares e relações sociais virtuais. Essas novas subjetividades virtuais, com seus reflexos no mundo real, ainda se constituem a contrapelo do espaço escolar, e o aspecto repressivo dessa relação mal resolvida costuma vir à tona quando se tornam públicos alguns trágicos eventos de cyberbulying, deixando gestores escolares e familiares atônitos diante dos casos de depressão e mesmo de suicídio que os acompanham. Os(as) estudantes ficaram então surpresos quando nossos(as) bolsistas, percebendo o comportamento dispersivo da turma, tiveram o insight de sugerir que as pesquisas sobre o período ditatorial fossem realizadas nas próprias redes sociais que Ihes eram preferidas.

${ }^{15}$ A exemplo do depoimento do Coronel Paulo Malhães, ex-agente do Centro de Informação do Exército e assassinado em 2014, no qual ele confessa ter participado de prisões e torturas durante a ditadura militar. 
Portanto, essa solução abriu as portas, por outro lado, para uma outra experiência de "trabalho de memória" sobre a ditadura de 1964-1985. Os "memes" compartilhados nas redes sociais tornaram-se as ferramentas capazes de conectar as "guerras de memória" do presente às problematizações afeitas à historiografia, uma vez que expressam de forma imediata o conjunto de lugares comuns por meio dos quais se confrontam as diferentes versões sobre os passados-presentes. Naquele momento os memes deixavam de ser vistos como meio de informação e passaram a ser percebidos como instrumentos políticos. Isso ficou patente quando os(as) estudantes foram convidados a compor um painel com os diversos memes que eles haviam selecionado na pesquisa anterior (Figuras 1, 2 e 3).

Essa atividade gerou entre os(as) estudantes a necessidade de chegarem a um acordo sobre o que poderia ou não compor aquele painel. 0 critério de visibilidade dos diferentes memes/versões sobre a ditadura de 1964-1985 deixou de ser, ali, apenas o número de "curtidas", "comentários", "compartilhamentos" ou "visualizações", mas um trabalho de argumentação capaz de mobilizar o conhecimento historiográfico e, por conseguinte, memórias mais justas. O critério democrático da atividade permitiu que um estudante ainda convencido da memória da negação/revisão da culpa do terror de Estado (ou que simplesmente ainda toma por diversão representar o polo "politicamente incorreto" da turma) pudesse se expressar no cantinho direito do painel. No entanto, sustentouse de maneira mais sólida o consenso construído coletivamente a partir de argumentações embasadas em critérios de validação historiográficos, e não mais meramente mercadológicos. 


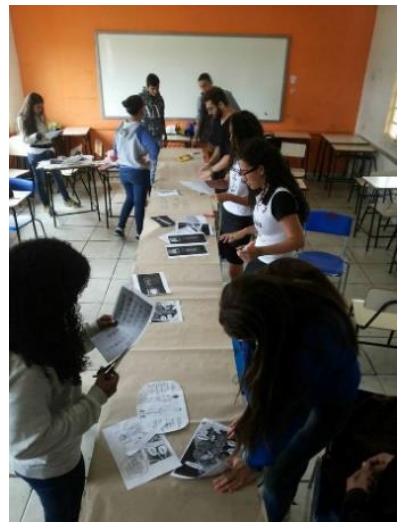

Fonte:

PIBID/História/UNIF

AL-MG

Figura 1 - Produção de um painel com memes sobre a ditadura de 1964-1985

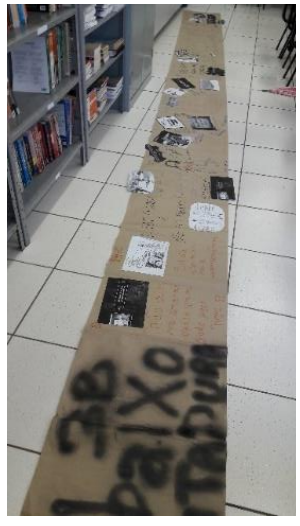

Fonte:

PIBID/História/UNIF

AL-MG

Figura 2 - Painel com memes sobre a ditadura de 1964-1985

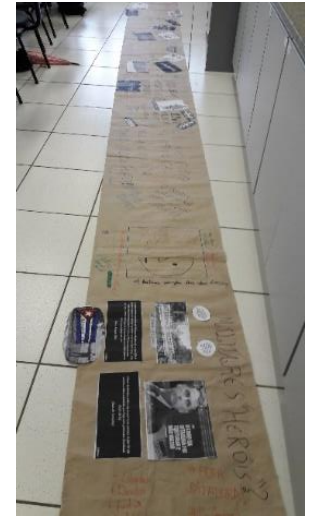

Fonte: PIBID/História/UNIF AL-MG

Figura 3 - Painel com memes sobre a ditadura de 1964-1985

\section{Considerações finais}

Seria possível utilizar as escolas públicas como "sítios de consciência" com o efeito pedagógico de evitar, no futuro, novas atrocidades perpetradas a partir do Estado? Segundo a International Coalition of Sites of Conscience (2017), um "sítio de consciência" se soma a pessoas e iniciativas que "ativam o poder dos lugares de memória para engajar o público na conexão do passado e do presente, a fim de prever e moldar um futuro mais justo e humano". ${ }^{16}$ No entanto, as escolas com as quais trabalhamos, não obstante estejam diretamente ligadas às ações educacionais da própria ditadura de 1964-85, período em que foram fundadas, têm funcionado, como vimos, muito mais como "lugares de esquecimento". Não encontramos nos edifícios nos quais atuamos nenhum tipo de investimento mnemônico capaz de usar essa materialidade escolar como símbolo de um passado tenebroso a ser evitado no presente, ainda que seus documentos e espaços estejam impregnados das diretrizes educacionais passadas ligadas aos projetos ditatoriais.

${ }^{16}$ Disponível em: http://www.sitesofconscience.org/pt/sobre-nos/.. Acesso em: 27 dez. 2017. 
Todavia, as ações ligadas à iniciação à docência que desenvolvemos nos mostraram que é possível "reativar" as memórias abafadas pela ditadura no espaço escolar. O maior exemplo disso foi a produção de uma "memória justa" a partir do "trabalho de memória" presente na construção do painel do qual tratamos acima e também das entrevistas cedidas pelas testemunhas do período. Essa ação possibilitou uma reapropriação das ferramentas impressas e digitais e dos espaços escolares a partir de uma prática orientada pela comunicação historiográfica, algo que nos permitiu fazer frente às "redes de memória" dirigidas pela negação/revisão do golpe.

Outras formas de ação, que não conseguimos empreender no período do qual dispusemos para a realização das nossas atividades, também poderiam ser exploradas. Podemos pensar na possibilidade de reativar as memórias sobre a ditadura de 1964-1985 (e outras memórias, talvez mais antigas mas não menos traumáticas) por meio da organização de documentos e depoimentos colhidos com outras pessoas ligadas à comunidade escolar, da interpretação histórica das arquiteturas escolares, da historicização das práticas e culturas escolares etc., apresentando-as em documentários, peças teatrais, festivais musicais e literários, em blogs e páginas de redes sociais etc., de modo a ocupar as diversas mídias existentes com memórias mais justas.

\section{Referências}

ADORNO, T. W.; HORKHEIMER, M. Dialética do esclarecimento: fragmentos filosóficos. [S.I.], [1947]. Disponível em:

https://nupese.fe.ufg.br/up/208/o/fil dialetica esclarec.pdf?1349572420. Acesso em: 03 jul. 2017.

BAGGIO, K. G. Conexões ultraliberais nas Américas: o think-tank norteamericano Atlas Network e suas vinculações com organizações latinoamericanas. In: ENCONTRO INTERNACIONAL DA ANPHLAC, 12., 2016, Campo Grande. Anais [...]. Campo Grande, MS, 2016.

BAUMAN, Z. Modernidade e holocausto. Rio de Janeiro: Zahar Ed., 1998.

BÉVORT, E.; BELLONI, M. L. Mídia-educação: conceitos, história e perspectivas. Educação Social, Campinas, v. 30, n. 109, p. 1081-1102, set./dez. 2009.

DELEUZE, G.; GUATTARI, F. Mil platôs: capitalismo e esquizofrenia. São Paulo: Ed. 34, 2004. v. 1. 
FICO, C. Ditadura militar brasileira: aproximações teóricas e historiográficas. Tempo e Argumento, Florianópolis, v. 9, n. 20, p. 5-74, jan./abr. 2017.

GUMBRECHT, H. U. Modernização dos sentidos. São Paulo: Editora 34, 1998.

IBGE. Brasil em síntese, panorama da cidade de Alfenas, Minas Gerais. Disponível em: https://cidades.ibge.gov.br/brasil/mg/alfenas/panorama. Acesso em: 28 dez. 2017.

INEP. Sinopse estatística da Educação Básica 2016. Brasília: INEP, 2017.

INTERNATIONAL COALITION OF SITES OF CONSCIENCE. "Sobre nós". 2017. Disponível em: http://www.sitesofconscience.org/pt/sobre-nos/. Acesso em: 28 dez. 2017.

LATOUR, B. Jamais fomos modernos: ensaio de antropologia simétrica. Rio de Janeiro: Ed. 34, 1994.

MALERBA, J. Acadêmicos na berlinda ou como cada um escreve a História?: uma reflexão sobre o embate entre historiadores acadêmicos e não acadêmicos no Brasil à luz dos debates sobre Public History. História da historiografia, Ouro Preto, n. 15, p. 27-50, ago. 2014.

MALERBA, J. Os historiadores e seus públicos: desafios ao conhecimento histórico na era digital. Revista Brasileira de História, São Paulo, v. 37, n. 74, p. 135-154, 2017.

MATTOS, M. B. O governo João Goulart: novos rumos da produção historiográfica. Revista Brasileira de História, São Paulo, v. 28, n. 55, p. 245263, 2008.

MELO, D. B. Ditadura "civil-militar"?: controvérsias historiográficas sobre o processo político brasileiro no pós-1964 e os desafios do tempo presente. Espaço plural, v. 13, n. 27, pp. 39-53, Jul./Dezembro 2012.

MÉSZÁROS, I. O século XXI: socialismo ou barbárie. São Paulo: Boitempo, 2003.

NAPOLITANO, M. O golpe de 1964 e o regime militar brasileiro: apontamentos para uma revisão historiográfica. Contemporânea, v. 2, n. 2, p. 209-217, 2011.

PEREIRA, M. H. F. Nova direita? Guerras de memória em tempos de Comissão da Verdade (2012-2014). Varia Historia, Belo Horizonte, v. 31, n. 57, p. 863-902, set./dez. 2015.

PEREIRA, M. H. F.; HERMETO, M. Justa memória, dívida, ética e passadospresentes dolorosos: questões a partir da análise de interpretações sobre a Ditadura Militar Brasileira (1964-1985) em livros didáticos de história. In MAIA, T. A.; ALVES, L. A. M.; HERMETO, M.; RIBEIRO, C. S. P. (Orgs.). (Re)Construindo o passado: o papel insubstituível do ensino da História. Porto Alegre: EdiPUCRS; Porto: CITCEM, 2016. 
PEREIRA, M. H. F.; PEREIRA, A. C. I. Os sentidos do golpe de 1964 nos livros didáticos de história (1970-2000): entre continuidades e descontinuidades. Tempo, v. 16, n. 30, pp. 197-220, 2011.

PINTO, A.; MÓDOLO, L. Big Data e a espoliação algorítmica dos dados: novos meios para uma velha dominação. Blog da Boitempo, 11 outubro 2017.

Disponível em: https://blogdaboitempo.com.br/2017/10/11/big-data-e-aespoliacao-algoritmica-dos-dados-novos-meios-para-uma-velha-dominacao/. Acesso em: 26 dez. 2017.

REIS FILHO, Daniel Aarão. (org.). Versões e ficções: o sequestro da história. São Paulo: Perseu Abramo, 1997.

ROCHA, H. A Ditadura Militar (1964-1985) nas narrativas didáticas brasileiras. Espacio, Tiempo y Educación, v. 2, n. 1, p. 97-120, 2015.

SEIGEL, M. Beyond compare: comparative method after the transnational turn. Radical History Review, v. 91, p. 62-90, Inverno 2005.

WAGNER, R. A invenção da cultura. São Paulo: Cosac Naify, 2010.

WEINSTEIN, B. Pensando a história fora da nação: a historiografia da América Latina e o viés transnacional. Revista eletrônica da ANPHILAC, n. 14, p. 9-36, jan./jun. 2013.

WERNER, M.; ZIMMERMANN, B. Pensar a história cruzada: entre empiria e reflexividade. Textos de História, v. 11, n. 1/2, p. 89-127, 2003. 